\title{
7
}

\section{Key Factors in Purpose Internalization}

\section{Carlos Rey, Frederic Marimon, and Marta Mas-Machuca}

As discussed in previous chapters, excelling at purpose internalization is a common trait of purpose-driven companies. Purpose internalization occurs when an organization's members integrate their personal beliefs and motivations with the organization's purpose. We also know from research done by The Harvard Business School ${ }^{1}$ that clarity of purpose throughout the organization has a positive impact on performance, suggesting that once purpose is discovered it must be clearly placed at the center of the company's narrative.

For such a feat to occur, companies typically embark on activities that foster an employee's purpose internalization through several means, such as videos, testimonies, and speeches. However, while defining and communicating your organization's purpose is one thing, getting your teams to internalize its meaning and scope is quite another. As we have seen in many cases, efforts to communicate the purpose do not always lead to employees taking true "ownership" of it. This was the case of a multinational IT solutions provider in Europe. The company had a great reputation in the marketplace, ranking

\section{Rey $(\bowtie)$}

Universitat Internacional de Catalunya,

Barcelona, Spain

e-mail: carlosrey@uic.es

F. Marimon • M. Mas-Machuca

Department of Economy and Business Organization, Universitat Internacional de Catalunya, Barcelona, Spain

e-mail: fmarimon@uic.es; mmas@uic.es 
high on the "best places to work" survey. However, it received poor results when graded on the degree to which its purpose was internalized among its employees. As a result, the company embarked on an intensive campaign to communicate its purpose. They used screensavers, videos, and posters throughout the office. The management gave inspiring speeches, referring often to the purpose and published articles about it in the company's internal magazine. Yet, after two years, the degree to which its purpose had been internalized was measured again and the same poor results were obtained.

Creating environments that enhance purpose internalization is indeed an art. However, a certain dose of science can help this art become much more effective. Start by asking, which means of communication might be most effective in transmitting the purpose and of those, which ones might best help your employees buy into the purpose?

To answer this questions, we developed a model for assessing purpose internalization across seven dimensions (see Table 7.1). Based on our empirical research, recently published in Industrial Management and Data Systems, ${ }^{2}$ we identified the best criteria for effective purpose communication. The results,

Table 7.1 Significance of the seven dimensions of purpose internalization

\section{Knowledge of the purpose}

The extent to which the employees know the purpose and are capable of explaining it in their own words.

2. Understanding the importance of the purpose

The extent to which the employees feel the purpose is relevant to them and for society.

3. Visible commitment from leadership (overlaps with 5)

The extent to which the managers of a company are committed to the purpose and make their decisions accordingly, thus providing visibility through their actions of their engagement to the purpose.

4. Visible commitment of co-workers

The extent to which employees feel that their colleagues are committed to the purpose.

5. Perceived coherence between purpose and practice (overlaps with 3)

The extent to which employees perceive that company decisions and day-to-day actions are consistent with the purpose.

\section{Reflecting on the purpose}

The extent to which employees participate in conceptualizing and giving their opinions relative to the purpose.

\section{Frequently recalling the purpose}

The extent to which a company formally and regularly communicates their purpose (placards, videos, speeches, etc.)
Significant

Significant

Significant

(most

relevant)

Significant

(most

relevant)

Significant

(most

relevant)

Significant

Non-significant

We consider "most relevant" load values $>0,7$ 
explained in this chapter along with practical examples and implications, identified six effective dimensions and one that, surprisingly, despite its common use, is ineffective.

\section{Knowledge of the Purpose}

Simple as it sounds, people must have explicit knowledge and a clear understanding of the purpose to the extent that they are able to explain it in their own words. Several studies demonstrate the need for purpose to be clearly communicated, ${ }^{3}$ paying special attention to how the message is interpreted, as well as to the feelings and emotions that the message provokes. Take for example, the pharmaceutical company Ferrer, whose purpose "to advance the wellbeing in society" has been made accessible and meaningful to all employees according to its HR manager, "thanks to the intensive communication of this simple statement." It has helped everyone, "from managers to factory employees, we use a common language when talking about our purpose." Another example is that of ISS, the Danish Facility Services company. They communicate their purpose to a workforce of half a million people in a very straight forward way: "we facilitate our customer's purpose." To better bring this purpose to its employees, ISS engages in emotional storytelling and talking about internal examples of how this has been accomplished. This helps all workers, from the cleaning staff to the maintenance team to the catering crew, who clearly understand their roles in living out this purpose through the work they do. ${ }^{4}$

When clear communication of the purpose and its content is lacking, organizations are more likely to develop confused messages, ${ }^{5}$ leading to ambiguity and lack of awareness. In such organizations employees struggle to explain their company's purpose in their own words.

\section{Understanding the Importance of the Purpose}

One way of accomplishing this is to make the purpose relatable to a greater cause and consistent with a generally accepted value system. It must be accepted as the correct way to think and act. For this reason, it is necessary to clearly explain that the company's purpose is good for not only employees but society at large. ${ }^{6}$ In order that employees understand the importance and need of purpose, organizations should consider using comprehensive arguments that relate the purpose to socially accepted values. A good example of this is 
the training program for managers at Bimbo. ${ }^{7}$ Before explaining the company's purpose, employees are encouraged to reflect upon their own purpose in life and the benefits of having one. Similarly, at Vygon, a French medical device company, the company periodically publishes stories on their intranet about people who achieved great feats and benefits thanks to a clear purpose. ${ }^{8}$

This dimension should not be ignored, because if employees fail to understand the importance and need for a purpose, it will play no role in their personal beliefs and values. In this case, purpose runs the risk of being perceived as "just another fad" or worse, seen by employees as a marketing ploy, out of context with the organization's various communication strategies.

\section{Visible Commitment from Leadership}

As suggested by many, "communicating purpose is the most central of all leadership behaviors" with the ability of employees to commit to purpose depending on this dimension. We have all seen examples of organizations that profess one thing but act completely different. It destroys credibility. This is equally true for purpose. The relevance of purpose is not so much the appeal of the message but the testimony as to its significance by company leaders. ${ }^{10}$ All too often, employees tend to appreciate their company's purpose but need confirmation that their "bosses" are truly committed in order to accept it. When a leader communicates the purpose with authenticity and constancy employees begin to believe in the purpose themselves: "the purpose is signaled from the top, and unfolds from the bottom." ${ }^{11}$

Our research showed that commitment, at the managerial level, had the greatest impact on whether or not purpose was internalized and positively embraced. These results are extremely important for their practical implications. Purpose has become such a popular topic that, "even leaders who don't fully believe face pressure from board members, investors, employees, and other stakeholders to communicate a higher purpose." ${ }^{12}$ But this would be completely ineffective as purpose requires deep engagement of managers. This might seem to be a simple idea, but it is not. Many companies devote significant resources and time to achieve a technically impressive campaign because they believe this singular approach is what leads to success. Yet, if employees still do not see a real commitment by the leadership to the message, then the communication will be ineffective. Even more troubling is that this approach could be fatally discouraging for employees who want to believe the message, because it will negatively impact trust in future communications coming from 
the top. The lack of trust in an organization's message can turn into a general lack of trust in its managers, and erode even further the morale of the employees, affecting their motivation and commitment. In short, the most powerful communication medium is the authentic behavior of the company's managers and leaders. This matters most.

For the founder of Bimbo, this has always been clear. ${ }^{13} \mathrm{He}$ holds that anyone in management positions should be a "leader of the purpose" and thus show his or her own responsibility and commitment to it. Something similar can be seen at the tier one automotive component supplier, HUF Portuguesa. ${ }^{14}$ Here, the purpose is at the center of the performance evaluation model by which all employees are graded. In every company in which we have worked, commitment from the managers is necessary for creating interdependent contributions. Without commitment, the purpose lacks legitimacy and will not be shared by employees.

\section{Visible Commitment of Co-workers}

Seeing the commitment of those around us to the company's purpose is significant because it forms the foundation of corporate identity and its shared belief system. For employees to internalize purpose, they must be convinced of the commitment of others in the organization, especially those with whom they interact regularly. ${ }^{15}$ This means we must be conscious of how purpose is ingrained in the company's culture. ${ }^{16}$

This dimension is considered by many to be a highly effective means for purpose to reach each and every employee more deeply. At JJC, a construction company in Peru, communicating their purpose is usually accompanied by images, examples, or phrases where employees show their personal commitment to the corporate purpose. This is similar at Jimenez Maña, a medium size company of automobile spare parts in Andalucía (Spain), where periodic videos and testimonies of employees appear on their intranet explaining the company's purpose and how it contributes to their work.

Our results show that a true test of management's commitment is the "perceived commitment of their co-workers." These findings are consistent with the idea that shared purpose requires shared leadership, and this serves to "demystify the notion of charismatic/transformational leadership." ${ }^{17}$ If employees do not see this commitment in their co-workers, it can lead to a sense that the company's purpose is something abstract, and that it does not necessarily affect them personally. 


\section{Perceived Coherence Between Purpose and Practice}

Coherence is present to the extent that an organization's daily actions and practices, experienced by employees, are aligned with the principles and direction set forth by its purpose. When companies are true to purpose, the daily activities of the organization will naturally provide ample evidence of the company's alignment to purpose. This is true for ISS, the Facility services provider, where the most seemingly trivial events, such as receiving a "thankyou" from a client, is communicated throughout the entire company as a sign of coherence to purpose. This is especially relevant when making difficult decisions that put the purpose to test, as may arise when a company faces the need for layoffs or fallout related to a public relations incident. The way the company acts in these situations, and equally important, how this is perceived by its employees, is crucial to the development of purpose. ${ }^{18}$

When a company truly lives its purpose, it becomes a "force" that elevates employee engagement. But if employees do not perceive coherence between purpose and practice, the purpose will lose credibility. Such a loss may occur due to ignorance or poor communication, especially among those employees who have limited knowledge about the general operations of the company. Hence it is important that the company "make a connection" by showing employees how their efforts benefit others. ${ }^{19}$

Our empirical analysis shows that perceived coherence between purpose and practice is significant to effective purpose internalization. However, we must note that, from the employees' perspective, point number 3 listed as visible commitment from leadership is identical to point number 5 perceived coherence between purpose and practice (see Table 7.1). In other words, employees identify the company's coherence with the management's commitment. Accordingly, both dimensions can be combined and considered jointly. This is consistent with the interconnection between internalization and implementation discussed in previous chapters. ${ }^{20}$ Even companies that practice their purpose, such as a healthcare company that aims to "improve people's lives," must ensure its employees see a commitment by top management to this purpose and if this is not the case (e.g., if they think that the managers only care about money), the company will be perceived as incoherent (or hypocritical) by its employees. 


\section{Reflecting on the Purpose}

For the purpose to come to life within an organization, there needs to be a means for people to reflect upon it. That is to say, it is not enough for only the top executives to consider the purpose, but rather it must be carried out consistently by all members of the company in such a way that it fosters a two-way communication. This is evident at the beauty products company, Biok, in Lithuania, where the various departments and areas engage each month in discussions about their purpose as well as their progress relative to its fulfillment. ${ }^{21}$ This is similar to a practice done at Alpha Omega, a high-tech neuroscience company in Israel, where employees all over the world are brought together in small groups to reflect upon their specific contribution to the purpose of the company. ${ }^{22}$ This level of intentional communication around purpose creates a positive environment, where employees are able to express their opinions about the purpose while at the same time build trust. Without such reflection, the purpose becomes what we might call an "apparent purpose" (or non-reflective), limiting it to a mere symbolic incorporation ${ }^{23}$ where employees regard the company's purpose as a formality, but do not internalize its meaning.

\section{Frequently Recalling the Purpose}

In our original research, we considered this dimension based on the belief that frequently recalling the purpose ensures it will be ever present in the company's and employee's internal dialogues. This is typically relayed through means such as posters, screensavers, short company-wide email messages, and so on. With these actions, the company seizes the opportunity, every day, to remind its people of its purpose. In this initial research, we considered that the image evoked by the purpose would be a source of employee satisfaction because when a purpose is authentic and linked to personal values and beliefs, people welcome reminders of that which "gives meaning" to their actions and efforts.

However, our analysis indicates that this is not significant for purpose internalization. We invite the reader to carefully consider these findings. Certainly, a practice such as this can be useful in the early stages of a new purpose communication or when there are significant changes in the purpose, but only as a reinforcement of the dimension stated as point number 1, knowing the content of purpose. Because a communication plan that is solely based on recalling the purpose will be completely ineffective for its internalization. Indeed, companies that excel in the other six dimensions will have no need to 
embark on such specific recollection practices, since the internal dialogue will naturally lead to keeping the purpose alive.

\section{Overall Effective Internalization}

The implications of this research are clear: organizations must move beyond mere tactics with regard to purpose communication, and guarantee that employees experience its essence in the workplace. In other words, a company's communication must be oriented to create the necessary environment in which the purpose can flourish and ultimately become shared by all its employees. In this sense, the six significant dimensions identified in our research offer a guide for getting the environment right. Indeed, although they have been presented here independently, in practice they are rarely isolated. For instance, when a CEO explains the company's purpose to her employees, she simultaneously reinforces both the "knowledge of" and "commitment to" the purpose. In fact, one clear recommendation from our research is that the dimensions must be developed coincidingly instead of employing only a few in piecemeal fashion. That is, if the company focuses on one or two dimensions alone, effective purpose communication is not likely to be achieved.

As a rule of thumb, our advice is to use the greatest possible number of dimensions discussed in this chapter. Every significant event of the company can be an opportunity to deploy some or even all of the dimensions, reinforcing their joint effectiveness and enhancing consistency in purpose internalization.

\section{Notes}

1. Gartenberg, C., Prat, A., \& Serafeim, G. (2019). Corporate purpose and financial performance. Organization Science.

2. Marimon, F., Mas-Machuca, M., \& Rey, C. (2016). Assessing the internalization of the mission. Industrial Management \& Data Systems, 116(1), 170-187.

3. Kopaneva, I., \& Sias, P. M. (2015). Lost in translation: Employee and organizational constructions of mission and vision. Management Communication Quarterly, 29(3), 358-384.

4. https://www.youtube.com/watch? $\mathrm{v}=\mathrm{z} 9 \mathrm{oMHg} 6 \mathrm{cYqs}$. Retrieved January 30, 2019. 
5. Kaplan, S. (2008). Framing contests: Strategy making under uncertainty. Organization Science, 19(5), 729-752.

6. Carton, A. M. (2018). "I'm not mopping the floors, I'm putting a man on the moon": How NASA leaders enhanced the meaningfulness of work by changing the meaning of work. Administrative Science Quarterly, 63(2), 323-369.

7. Worldwide leading bakery Mexican multinational with more than 130,000 employees.

8. https://www.youtube.com/watch?v=aPMnQHzqZGM\&list=PLUOl1IsE77 bwsfbV9IRbt4GYaFNRlaCCM\&index=3. Retrieved January 30, 2019.

9. Carton, A. M., Murphy, C., \& Clark, J. R. (2014). A (blurry) vision of the future: How leader rhetoric about ultimate goals influences performance. Academy of Management Journal, 57(6), 1544-1570.

10. Hollensbe, E., Wookey, C., Hickey, L., George, G., \& Nichols, C. V. (2014). Organizations with purpose. Academy of Management Journal, 57(5), $1227-1234$.

11. Quinn, R. E., \& Thakor, A. V. (2018, July-August). Creating a PurposeDriven Organization. Harvard Business Review, pp. 78-85.

12. Ibidem.

13. Lorenzo Servitje (1918-2017).

14. https://www.youtube.com/watch?v=QftQxPKhqG8. Retrieved January 30, 2019.

15. White, A., Yakis-Douglas, B., Helanummi-Cole, H., \& Ventresca, M. (2017). Purpose-led organization: "Saint Antony" reflects on the idea of organizational purpose, in principle and practice. Journal of Management Inquiry, 26(1), 101-107.

16. Almandoz, J., Lee, Y., \& Ribera, A. (2018). Unleashing the power of purpose: 5 steps to transform your business, IESE Insight, 37, Second Quarter, 44-51.

17. Bono, J. E., \& Judge, T. A. (2003). Self-concordance at work: Toward understanding the motivational effects of transformational leaders. Academy of Management Journal, 46(5), 554-571.

18. Birkinshaw, J., Foss, N. J., \& Lindenberg, S. (2014). Combining purpose with profits. MIT Sloan Management Review, 55(3), 49.

19. Grant, A. M. (2012). Leading with meaning: Beneficiary contact, prosocial impact, and the performance effects of transformational leadership. Academy of Management Journal, 55(2), 458-476.

20. See Chap. 3.

21. https://www.youtube.com/watch?v=xI1Cg2FkrxM. Retrieved January 30, 2019.

22. https://www.youtube.com/watch?v=ejLoKiBzL94\&t=237s. Retrieved January 30, 2019.

23. Gondo, M. B., \& Amis, J. M. (2013). Variations in practice adoption: The roles of conscious reflection and discourse. Academy of Management Review, 38(2), 229-247. 
Open Access This chapter is licensed under the terms of the Creative Commons Attribution 4.0 International License (http://creativecommons.org/licenses/by/4.0/), which permits use, sharing, adaptation, distribution and reproduction in any medium or format, as long as you give appropriate credit to the original author(s) and the source, provide a link to the Creative Commons licence and indicate if changes were made.

The images or other third party material in this chapter are included in the chapter's Creative Commons licence, unless indicated otherwise in a credit line to the material. If material is not included in the chapter's Creative Commons licence and your intended use is not permitted by statutory regulation or exceeds the permitted use, you will need to obtain permission directly from the copyright holder. 